\title{
Estimating cloud condensation nuclei concentrations from CALIPSO lidar measurements
}

\author{
Goutam Choudhury and Matthias Tesche \\ Leipzig Institute for Meteorology (LIM), Leipzig University, Stephanstrasse 3, 04103 Leipzig, Germany \\ Correspondence: Goutam Choudhury (goutam.choudhury@uni-leipzig.de)
}

Received: 26 October 2021 - Discussion started: 28 October 2021

Revised: 11 December 2021 - Accepted: 10 January 2022 - Published: 8 February 2022

\begin{abstract}
We present a novel methodology to estimate cloud condensation nuclei $(\mathrm{CCN})$ concentrations from spaceborne CALIPSO (Cloud-Aerosol Lidar and Infrared Pathfinder Satellite Observations) lidar measurements. The algorithm utilizes (i) the CALIPSO-derived backscatter and extinction coefficient, depolarization ratio, and aerosol subtype information; (ii) the normalized volume size distributions and refractive indices from the CALIPSO aerosol model; and (iii) the MOPSMAP (modelled optical properties of ensembles of aerosol particles) optical modelling package. For each CALIPSO height bin, we first select the aerosol-type specific size distribution and then adjust it to reproduce the extinction coefficient derived from the CALIPSO retrieval. The scaled size distribution is integrated to estimate the aerosol number concentration, which is then used in the $\mathrm{CCN}$ parameterizations to calculate $\mathrm{CCN}$ concentrations at different supersaturations. To account for the hygroscopicity of continental and marine aerosols, we use the kappa parameterization and correct the size distributions before the scaling step. The sensitivity of the derived $\mathrm{CCN}$ concentrations to variations in the initial size distributions is also examined. It is found that the uncertainty associated with the algorithm can range between a factor of 2 and 3. Our results are comparable to results obtained using the POLIPHON (Polarization Lidar Photometer Networking) method for extinction coefficients larger than $0.05 \mathrm{~km}^{-1}$. An initial application to a case with coincident airborne in situ measurements for independent validation shows promising results and illustrates the potential of CALIPSO for constructing a global height-resolved CCN climatology.
\end{abstract}

\section{Introduction}

Aerosol particles act as cloud condensation nuclei (CCN) and ice-nucleating particles (INPs) and provide a surface for the condensation of atmospheric water vapour to form cloud droplets. The physical and chemical properties of such particles affect not only the cloud micro- and macro-physical properties, but also cloud development, lifetime, and the associated precipitation (Rosenfeld et al., 2014; Fan et al., 2016; Choudhury et al., 2019). The rapid adjustments in clouds resulting from aerosol-cloud interactions (ACIs) are not well understood and still remain the largest source of spread in global climate projections (IPCC, 2021). This challenge has motivated the scientific community to study ACIs by using data from in situ and satellite measurements as well as by means of modelling and simulations.

Satellites provide long-term global coverage that enables ACI studies with constrained meteorology and cloud regimes (Oreopoulos et al., 2017; Douglas and L'Ecuyer, 2019; Jia et al., 2021). Satellite-based ACI studies relate cloud parameters (cloud reflectivity or albedo, cloud optical depth, cloud fraction, cloud drop effective radius, liquid water path), aerosol properties (aerosol optical depth (AOD), Ångström exponent (AE), aerosol index (AI)), and the precipitation pattern to understand the underlying mechanisms (Quaas et al., 2008, 2020; Gryspeerdt and Stier, 2012; McCoy et al., 2017; Kant et al., 2019; Liu et al., 2020; Choudhury et al., 2020). The use of AOD and (to a lesser extent) AI as CCN proxies results in a significant underestimation of the radiative forcing due to ACIs (Gryspeerdt et al., 2017; Hasekamp et al., 2019). Shinozuka et al. (2015) suggest that the satellitederived AOD or AI, being a column-integrated product, may not be the appropriate proxies for cloud-relevant $\mathrm{CCN}$ particles that usually lie close to the cloud base. Moreover, 
Stier (2016) found a low correlation $(<0.5)$ between the ECHAM-HAM model-simulated AOD and CCN concentration near the cloud base and suggested the use of vertically resolved measurements from spaceborne lidar for ACI studies. The findings of Dusek et al. (2006) show that the ability of aerosols to act as $\mathrm{CCN}$ is predominantly dependent on their size rather than composition. This facilitates the use of satellite-derived aerosol number concentrations as accurate $\mathrm{CCN}$ proxies for ACI studies (Gryspeerdt et al., 2017; Hasekamp et al., 2019). The PSML003_Ocean data included in the MODIS (Moderate Resolution Imaging Spectroradiometer) ocean product give the aerosol number concentration with a radius greater than or equal to $30 \mathrm{~nm}$ or $n_{30}$ (Remer et al., 2005, Appendix B). This product is formed by matching the spectral radiance measured by MODIS to the radiance estimated from a combination of the microphysical properties (size distributions and refractive indices) of nine aerosol types. However, the column-integrated $n_{30}$ is proportional to the AOD and may not represent the atmospheric CCN particles located close to the cloud base altitudes (Shinozuka et al., 2015).

Lidar measurements provide height-resolved aerosol optical properties which are crucial to study vertically co-located aerosols and clouds (Costantino and Bréon, 2013). Mamouri and Ansmann (2015) for the first time presented the Polarization Lidar Photometer Networking (POLIPHON) technique to estimate INP concentrations from lidar-derived extinction coefficient for desert dust aerosols. The algorithm first converts the extinction coefficient to aerosol number concentration with radius $>250 \mathrm{~nm}\left(n_{250}\right)$ by using conversion factors derived from the Aerosol Robotic Network (AERONET) correlation study. The INP concentration is then calculated from $n_{250}$ using the parameterizations from DeMott et al. (2010, 2015). Mamouri and Ansmann (2016) further extend the methodology for estimating $\mathrm{CCN}$ concentrations at different supersaturation from lidar-derived extinction coefficient for dust, continental and marine aerosols, and more recently for aged and fresh smoke aerosols (Ansmann et al., 2021b). The POLIPHON technique to estimate CCN and INP concentrations is not only limited to ground-based lidars but can also be applied to the spaceborne lidar CALIOP (Cloud-Aerosol Lidar with Orthogonal Polarization) aboard the CALIPSO (Cloud-Aerosol Lidar and Infrared Pathfinder Satellite Observations) polar-orbiting satellite (Marinou et al., 2019; Georgoulias et al., 2020). Georgoulias et al. (2020) for the first time estimated CCN concentrations from CALIPSO measurements by using the POLIPHON technique and found good agreement with the coincident airborne in situ measurements taken during the ACEMED-EUFAR (evaluation of CALIPSO's aerosol classification scheme over the eastern Mediterranean) campaign (Tsekeri et al., 2017). This illustrates the potential of spaceborne lidar measurements to construct global 3D CCN and INP data sets.
The CALIPSO aerosol model includes a set of normalized volume size distributions (NVSDs) and refractive indices of six aerosol subtypes (Omar et al., 2009). Similar to the MODIS PSML003_Ocean algorithm, these microphysical properties along with the CALIPSO-measured aerosol optical properties can be used to derive the cloud-relevant aerosol number concentrations. In the present work, we utilize the CALIPSO aerosol model to calculate the extinction coefficient by using Mie scattering for spherical particles (continental and marine aerosols) and a combination of a T-matrix method and an improved geometric optics method for non-spherical particles (dust aerosols). We then modify the NVSD by preserving its shape (mode radii and standard deviation remain constant) until a closure is achieved between the extinction coefficient inferred from CALIPSO measurements and derived through light-scattering calculations. We finally use the modified size distribution to compute the aerosol number concentration favourable to act as $\mathrm{CCN}$ by using the $\mathrm{CCN}$ parameterizations that correspond to different aerosol types (Mamouri and Ansmann, 2016). Further, we carry out sensitivity tests by varying the initial NVSD to quantify the uncertainty associated with the retrieval algorithm. We compare our results with the existing CCN retrieval algorithm POLIPHON for different aerosol subtypes. Moreover, we present a case study where we apply our algorithm to a CALIPSO overpass over Thessaloniki and compare it with the in situ observations taken during the ACEMED-EUFAR campaign (Tsekeri et al., 2017). The approach for retrieving cloud-relevant aerosol microphysical properties has not yet been implemented for spaceborne lidar measurements. This study, therefore, presents a new methodology for obtaining height-resolved aerosol number concentrations from CALIPSO measurements within the CALIPSO framework, i.e. without relying on externally inferred conversion factors.

The paper is structured as follows. The data, optical modelling package used in this work, and a brief overview of the POLIPHON technique for retrieving CCN concentrations from lidars are described in Sect. 2. Section 3 describes our $\mathrm{CCN}$ retrieval algorithm for spaceborne lidar. The sensitivity analysis and comparison studies are presented in Sect. 4. We conclude the paper with a summary in Sect. 5 .

\section{Data and retrievals}

\subsection{CALIPSO}

CALIPSO is a sun-synchronous polar-orbiting satellite launched on 28 April 2006, as a part of the afternoon or A-Train constellation (Winker et al., 2009). CALIOP is a polarization-sensitive lidar onboard CALIPSO that measures profiles of aerosol and cloud properties from an elevation of $30 \mathrm{~km}$ above mean sea level to the surface. The CALIPSO algorithm classifies the measured signal into aerosols, clouds, 
clear air, and surface and assigns a subtype to the detected aerosol signals (Omar et al., 2009). CALIPSO has a set of lidar ratios associated with each aerosol subtype. These lidar ratios are used in the CALIPSO retrieval algorithm to estimate the aerosol extinction and backscatter coefficient. In this work, we use the CALIPSO version 4.20 level 2 aerosol profile product with a uniform horizontal resolution of $5 \mathrm{~km}$. Because of CALIPSO's data averaging scheme, the vertical resolution of aerosol profile data varies with altitude. It is $60 \mathrm{~m}$ for altitudes between 20 and $-0.5 \mathrm{~km}$ and $180 \mathrm{~m}$ above $20 \mathrm{~km}$. We use the profiles of aerosol extinction coefficient, backscatter coefficient, and particle depolarization ratio measured at $532 \mathrm{~nm}$ and the aerosol subtype information in the $\mathrm{CCN}$ retrieval algorithm. We also use the relative humidity profiles included in the CALIPSO data product, obtained by the Global Modelling and Assimilation Office Data Assimilation System (Molod et al., 2015).

The CALIPSO version 2 aerosol types include dust, smoke, clean continental, polluted continental, clean marine, and polluted dust. The microphysical properties of these six aerosol subtypes constitute the CALIPSO aerosol model (CAMel). The lidar ratios used in the retrieval of extinction coefficient for each aerosol type were modelled using these microphysical properties. Of the six aerosol subtypes, the properties of smoke, polluted continental, and polluted dust were obtained directly from a cluster analysis of long-term cloud-screened AERONET measurements (Omar et al., 2005). The dust model was derived from Kalashnikova and Sokolik (2002), and the clean marine model was derived from the dry measurements taken during the Shoreline Environment Aerosol Study (SEAS) campaign (Masonis et al., 2003; Clarke et al., 2003). The clean continental model was formed by adjusting the properties of the background continental aerosol cluster from Omar et al. (2005) to measurements of Anderson et al. (2000). The aerosol model has evolved with time. In version 4 , a new aerosol subtype, namely the dusty marine (dust and marine), was introduced. Further, the polluted continental and smoke subtypes were renamed to polluted continental/smoke and elevated smoke, respectively (Kim et al., 2018). The lidar ratios were also modified, leading to an increase in mean AOD by $52 \%(40 \%)$ for nighttime (daytime) retrievals, making it more comparable with MODIS-derived AOD. In our algorithm, we use the microphysical properties of five aerosol subtypes, namely marine, dust, polluted continental/smoke, clean continental, and elevated smoke. Note that the lidar ratios used in version 4 of the CALIPSO retrieval have been adjusted from earlier versions based on the findings from atmospheric measurements (Kim et al., 2018) and do not necessarily connect to the CALIPSO aerosol model. Since the changes in lidar ratio from version 2 to version 4 are minor $(\leq 1 \%)$ for all aerosol types except for clean continental $(51 \%)$, we believe the aerosol model can still be used in our algorithm. However, for the case of the clean continental aerosol subtype, further study is required to estimate the ef- fect of change in lidar ratio on its microphysical properties. Having said that, we do not exclude it from our analysis for the completeness of our algorithm, leaving a scope of future validation study to examine its applicability in estimating the $\mathrm{CCN}$ concentrations from CALIPSO.

\subsection{MOPSMAP package}

The modelled optical properties of ensembles of aerosol particles (MOPSMAP) package provides the aerosol optical properties of arbitrary, randomly oriented spherical or spheroidal particle ensembles for size parameters ranging up to 1000 and a refractive index range of $[0.1,3.0]$ and $[0,2.2]$ for real and imaginary parts, respectively (Gasteiger and Wiegner, 2018). It includes a data set of pre-calculated aerosol optical properties and a Fortran program, which estimates the properties of user-defined aerosol ensembles. The optical properties of spherical particles are modelled using Mie scattering. While for spheroids, based on the aerosol size parameter, MOPSMAP uses a combination of the T-matrix method and improved geometric optics method. MOPSMAP has been used to simulate the optical properties of different aerosol types such as mineral (silica and alumina) and ash aerosols (Jiang et al., 2021) and Martian dust aerosols (ChenChen et al., 2021). We apply the MOPSMAP package to model the aerosol extinction coefficient of different aerosol subtypes with the bimodal log-normal volume size distributions and refractive indices from CAMel. The details of the MOPSMAP input parameters are discussed in the methodology section.

\subsection{POLIPHON}

The POLIPHON technique enables the retrieval of aerosol number concentration by combining the ability of polarization lidar to measure aerosol-type-specific optical properties with long-term AERONET measurements of aerosol microphysical properties and AOD (Shinozuka et al., 2015; Mamouri and Ansmann, 2015, 2016). It converts the lidarderived extinction coefficient ( $\alpha$ in $\mathrm{km}^{-1}$ ) to number concentration of aerosols with a dry radius greater than $100 \mathrm{~nm}$ $\left(n_{100, \text { dry }}\right)$ for dust aerosols and greater than $50 \mathrm{~nm}\left(n_{50, \text { dry }}\right)$ for marine and continental aerosols as

$n_{j, \mathrm{dry}}=C \cdot \alpha^{x}(z)$,

where $n_{j, \text { dry }}$ represents the total aerosol concentration with a dry radius greater than $j \mathrm{~nm}, C$ is the conversion factor $\left(\mathrm{cm}^{-3} \mathrm{Mm}\right)$, and $x$ is the aerosol extinction exponent. The value of $j$ is $50 \mathrm{~nm}$ for continental and marine aerosols and $100 \mathrm{~nm}$ for dust aerosols. The constants $C$ and $x$ are calculated from the $\log n_{j, \text { dry }}-\log \alpha$ regression analysis of AERONET measurements, and their values used in this work are listed in Table 1. 
Table 1. POLIPHON conversion factors $(C)$ and extinction exponents $(x)$ for different aerosol subtypes.

\begin{tabular}{lrrl}
\hline Type & $C$ & $x$ & Source \\
\hline Dust & 8.855 & 0.7525 & Ansmann et al. (2019) \\
Continental & 25.3 & 0.94 & Mamouri and Ansmann (2016) \\
Marine & 7.2 & 0.85 & Mamouri and Ansmann (2016) \\
Smoke & 17 & 0.79 & Ansmann et al. (2021b) \\
\hline
\end{tabular}

The CCN concentration at a certain supersaturation is estimated from the aerosol number concentration as

$n_{\mathrm{CCN}}=f_{\mathrm{ss}} \cdot n_{j, \mathrm{dry}}$,

where $f_{\mathrm{ss}}=1.0,1.35$, and 1.7 for supersaturations of $0.15 \%$, $0.25 \%$, and $0.40 \%$, respectively. In this study, we use the conversion factors and extinction exponents for continental and marine aerosols from Mamouri and Ansmann (2016). For dust aerosols, we use the globally averaged values as suggested by Ansmann et al. (2019) for application to satellite data. For smoke aerosols, we use the aged smoke conversion factor and extinction exponent values from Ansmann et al. (2021b).

\section{Methodology}

This section describes the algorithm used in the present work to derive $\mathrm{CCN}$ concentrations from the CALIPSO profiles of extinction coefficient, backscatter coefficient, depolarization ratio, and aerosol subtype information. We begin with the scaling procedure of the normalized size distributions from CAMel to obtain the actual aerosol size distribution. After that, we explain the hygroscopicity correction followed by the CCN parameterization adopted in our algorithm. Finally, we discuss the application of the $\mathrm{CCN}$ retrieval algorithm to CALIPSO level 2 aerosol profile data.

\subsection{Aerosol size distribution}

The remote sensing of aerosol number concentration requires an initial assumption of aerosol microphysical properties (size distribution and refractive index). For instance, the MODIS algorithm over the ocean uses a combination of nine predefined aerosol size distributions and refractive indices and selects the one for which the difference in the measured and modelled radiance is minimum (Appendix B of Remer et al., 2005). In our study, we use the aerosol microphysical properties from CAMel and adopt a two-step algorithm to derive the aerosol size distribution: (i) select the appropriate initial normalized volume size distribution and refractive index, and (ii) scale the size distribution as per the CALIPSOmeasured extinction coefficient. In contrast to MODIS, the aerosol type in CALIPSO is set prior to the computation of the extinction coefficient. This eases the selection of initial aerosol microphysics, which can now be done directly from CAMel as per the aerosol subtype information included in the CALIPSO retrieval.

The next step is to scale the NVSD as per the CALIPSOmeasured extinction. The extinction coefficient $(\alpha)$ for a certain incident wavelength can be described as

$\alpha=\int_{r_{\min }}^{r_{\max }} \frac{K_{\alpha}(m, r)}{V(r)} \cdot \frac{\mathrm{d} V(r)}{\mathrm{d} \ln r} \cdot \mathrm{d} \ln r$,

where $r$ is the particle radius; $V(r)$ is the volume of the particle with radius $r ; K_{\alpha}$ is the extinction cross section, which is a function of the complex refractive index $(m)$ and $r$; and $\mathrm{d} V(r) / \mathrm{d} \ln r$ is the log-normal volume size distribution, which for a bimodal case can be given by

$$
\frac{\mathrm{d} V(r)}{\mathrm{d} \ln r}=V_{\mathrm{t}} \cdot \sum_{i=1}^{2} \frac{v_{i}}{\sqrt{2 \pi} \ln \sigma_{i}} \exp \left(\frac{-\left(\ln r-\ln \mu_{i}\right)^{2}}{2 \ln \sigma_{i}{ }^{2}}\right) .
$$

Here, $v_{i}, \sigma_{i}$, and $\mu_{i}$ are the volume fractions, geometric standard deviations, and geometric mean radii of the $i$ th mode, respectively. $V_{\mathrm{t}}$ is the total volume of the size distribution. The above size distribution is normalized when $V_{\mathrm{t}}=1$. Substituting Eq. (4) in Eq. (3), we get

$$
\begin{aligned}
\alpha= & V_{\mathrm{t}} \cdot \int_{r_{\min }}^{r_{\max }} \frac{K_{\alpha}(m, r)}{V(r)} \cdot \sum_{i=1}^{2} \frac{v_{i}}{\sqrt{2 \pi} \ln \sigma_{i}} \\
& \cdot \exp \left(\frac{-\left(\ln r-\ln \mu_{i}\right)^{2}}{2 \ln \sigma_{i}^{2}}\right) \cdot \mathrm{d} \ln r .
\end{aligned}
$$

Thus, the extinction coefficient is a function of the size distribution parameters $\left(V_{\mathrm{t}}, v_{i}, \sigma_{i}\right.$, and $\left.\mu_{i}\right)$ and the extinction cross section $\left(K_{\alpha}\right)$. Out of these parameters, under ideal conditions, only $V_{\mathrm{t}}$ is an extensive property, while the rest are intensive and independent of aerosol amount or concentration (Omar et al., 2005). Equation (5) can be simplified to

$\alpha=V_{\mathrm{t}} \cdot \alpha_{\mathrm{n}}$,

where $\alpha_{\mathrm{n}}$ is the normalized extinction coefficient corresponding to the NVSD. If we consider $\alpha$ as the CALIPSOmeasured extinction, $V_{\mathrm{t}}$ would be the scaling factor for the NVSD to compute the actual aerosol size distribution. From Eq. (6), we can compute $V_{\mathrm{t}}$ if the value of $\alpha_{\mathrm{n}}$ is known.

We estimate $\alpha_{\mathrm{n}}$ for each aerosol subtype by using the NVSDs and refractive indices from CAMel as input to the MOPSMAP optical modelling package. In the MOPSMAP input, we consider dust as spheroids and use the axis ratio distribution from Dubovik et al. (2006) (also used in the AERONET inversion). Other aerosol subtypes are considered spheres. We then compute $V_{\mathrm{t}}$ from the ratio of $\alpha$ and $\alpha_{\mathrm{n}}$ (Eq. 6). On multiplying $V_{\mathrm{t}}$ with the NVSD, we get the final scaled aerosol size distribution. Since the algorithm principally relies on the optical modelling of CALIPSO aerosol microphysics, we hereafter refer to it as OMCAM. 


\subsection{Aerosol hygroscopicity}

The hygroscopic aerosol particles in the atmosphere can uptake water and grow in moist conditions. The hygroscopic growth needs to be accounted for before deriving the $\mathrm{CCN}$ concentrations. We consider continental (clean continental, polluted continental/smoke, and elevated smoke) and marine aerosols as hygroscopic. We assume dust aerosols to be hydrophobic in accordance with previous studies (Mamouri and Ansmann, 2016; Ansmann et al., 2019). The hygroscopicity correction can be applied either to the ambient extinction coefficient measured by CALIPSO or to the initial NVSD in the retrieval algorithm. We consider the latter approach and modify the initial NVSD before modelling the extinction coefficient. There is an inbuilt functionality in the MOPSMAP package to account for the hygroscopicity using the kappa parameterization scheme (Petters and Kreidenweis, 2007; Zieger et al., 2013) as

$$
\frac{r_{\text {wet }}(\mathrm{RH})}{r_{\text {dry }}}=\left(1+\kappa \cdot \frac{\mathrm{RH}}{100-\mathrm{RH}}\right)^{\frac{1}{3}} \text {, }
$$

where $\mathrm{RH}$ is the relative humidity, and $\kappa$ is the hygroscopic growth parameter. The $r_{\min }, r_{\max }$, and $\mu$ of the lognormal size distribution (Eq. 5) are multiplied with this ratio, whereas the standard deviation $(\sigma)$ remains unchanged. The refractive index of the hygroscopic aerosol is also modified following the volume-weighting rule (Gasteiger and Wiegner, 2018). The $\kappa$ value is set to be 0.3 for continental and 0.7 for marine aerosols. The values are global averages and are suggested by Andreae and Rosenfeld (2008).

\subsection{CCN parameterizations}

We use the parameterizations listed in Mamouri and Ansmann (2016) to estimate CCN concentrations from the dry aerosol number concentration. The final scaled aerosol volume size distribution obtained from the scaling procedure is first converted to number size distribution. The number size distribution is integrated starting at 50 or $100 \mathrm{~nm}$ to compute

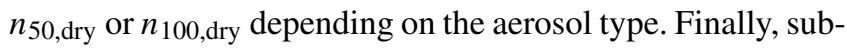
stituting the values in Eq. (2) results in the required CCN concentration at different supersaturations.

\subsection{Application of OMCAM to CALIPSO retrieval}

Figure 1 outlines the OMCAM retrieval algorithm for estimating $\mathrm{CCN}$ concentrations from CALIPSO measurements. In order to apply the OMCAM algorithm to CALIPSO level 2 version 4.20 data, we first start by pre-processing the data set. To begin with, we apply all the quality filters listed in Tackett et al. (2018, Table 1). The CALIPSO aerosol typing algorithm consists of dust mixtures (dusty marine and polluted dust). In such a case, we separate the dust and nondust extinction coefficients by using the methodology given in Tesche et al. (2009). This is a rather simple and accepted dust separation technique also used by Mamouri and Ansmann $(2015,2016)$ for lidar-based CCN retrieval. It uses the particle depolarization ratio $\left(\delta_{\mathrm{p}}\right)$ to separate the particle backscatter coefficient $\left(\beta_{\mathrm{p}}\right)$ into dust $\left(\beta_{\mathrm{d}}\right)$ and non-dust $\left(\beta_{\mathrm{nd}}\right)$ contributions. $\beta_{\mathrm{d}}$ can be calculated as

$\beta_{\mathrm{d}}=\beta_{\mathrm{p}} \frac{\left(\delta_{\mathrm{p}}-\delta_{2}\right)\left(1+\delta_{1}\right)}{\left(\delta_{1}-\delta_{2}\right)\left(1+\delta_{\mathrm{p}}\right)}$,

where the values of $\delta_{1}$ and $\delta_{2}$ are 0.31 and 0.05 , respectively. The aerosol mixture is assumed to be pure dust (non-dust) when $\delta_{\mathrm{p}}>0.31(<0.05)$. When $0.05 \leq \delta_{\mathrm{p}} \leq 0.31$, we first estimate $\beta_{\mathrm{d}}$ from Eq. (8) and then calculate $\beta_{\text {nd }}$ by subtracting $\beta_{\mathrm{d}}$ from $\beta_{\mathrm{p}}$. We compute the dust and non-dust extinction coefficient by multiplying the backscatter coefficient by the respective lidar ratio. The lidar ratios of dust, polluted continental, and clean marine aerosol subtypes are taken from Kim et al. (2018) and are equal to 44, 70, and 23, respectively. The extinction coefficient of polluted dust is separated into polluted continental/smoke and dust, while that of dusty marine is separated into dust and marine contributions. Finally, the extinction coefficient, relative humidity, and aerosol subtype information is passed to the $\mathrm{CCN}$ retrieval algorithm.

In the $\mathrm{CCN}$ retrieval part, we first select the normalized size distribution and refractive index as per the aerosol subtype and modify them as per the RH value so as to account for the hygroscopicity of aerosols. In the next step, we model the extinction coefficient using the MOPSMAP package and calculate $V_{\mathrm{t}}$ from Eq. (6). Multiplying $V_{\mathrm{t}}$ by the initial dry normalized size distribution gives the final dry aerosol size distribution, which is used in the $\mathrm{CCN}$ parameterizations (Eq. 2) to estimate the $\mathrm{CCN}$ concentrations at different supersaturation values. This methodology is applied to every bin of the CALIPSO profile. In the case of dust mixtures, the separated dust and non-dust extinction coefficients are passed through the $\mathrm{CCN}$ retrieval algorithm individually, and the results are finally added to compute the net $\mathrm{CCN}$ concentration for that bin. It is worthwhile to note that this algorithm can in principle be used to derive INP concentration from CALIPSO measurements. This can be done by first estimating $n_{250}$ from the modified size distribution (Sect. 3.1) and then using the INP parameterizations (DeMott et al., 2010, 2015) to estimate INP concentrations. However, in the present study, we limit our focus to retrieving the $\mathrm{CCN}$ concentrations.

\section{Results}

\subsection{Sensitivity analysis}

The performance of OMCAM in retrieving $\mathrm{CCN}$ concentrations primarily relies on the initial NVSD given in CAMel. The aerosol size distributions may change depending on the age and composition of aerosols (region and type dependent) and the ambient meteorology. As most of the size distribu- 


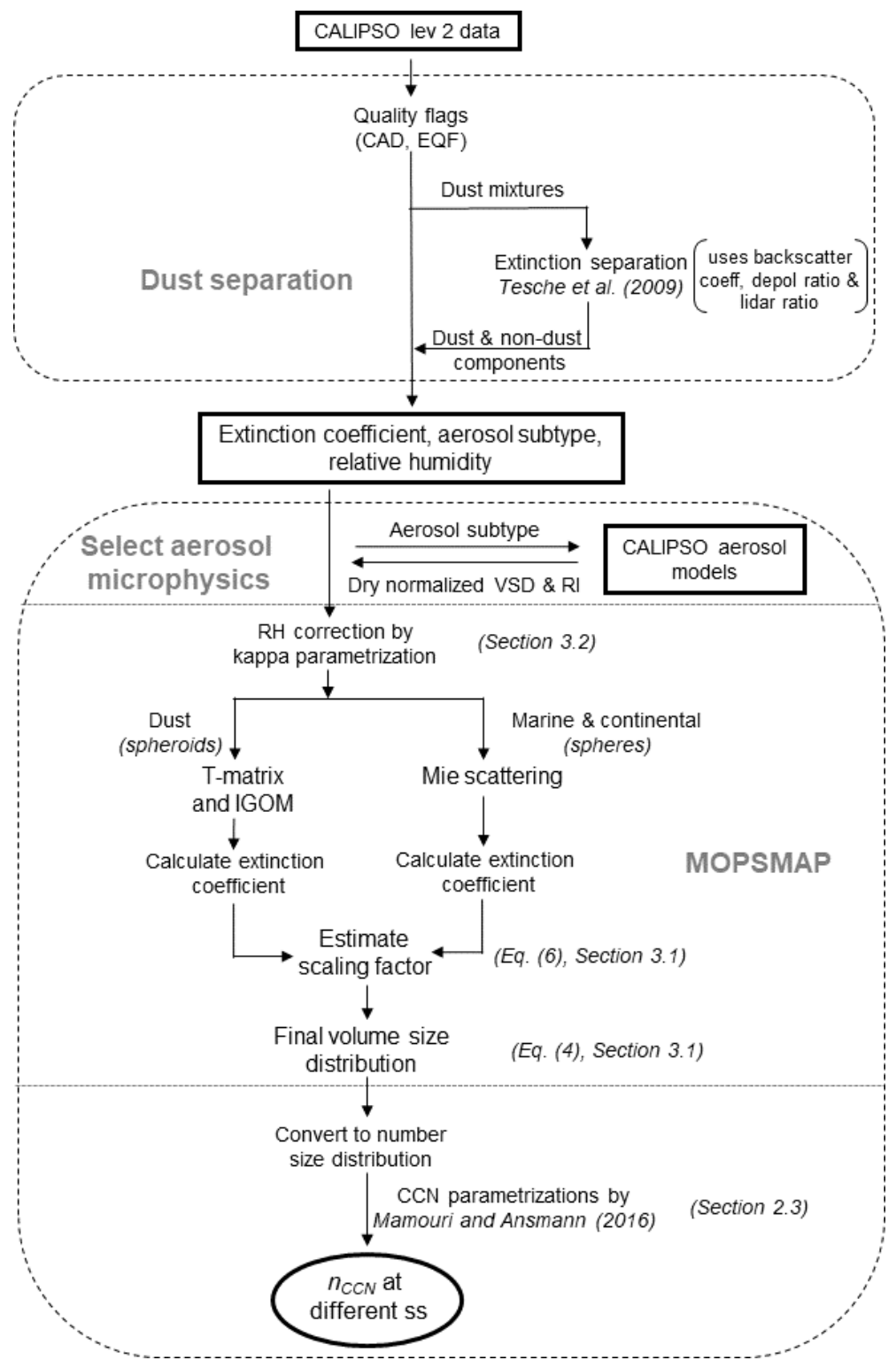

Figure 1. Flowchart of the OMCAM algorithm illustrating important steps involved in retrieving CCN concentrations from CALIPSO level 2 aerosol profile data. The upper part describes the pre-processing to infer information on the extinction coefficient, aerosol subtype, and the relative humidity. These parameters form the input to the $\mathrm{CCN}$ retrieval part, which is outlined in the lower part. The chart also refers to the used equations and the sections in which specific parts are discussed.

tions used in CAMel are derived from cluster analysis of the long-term AERONET measurements (see Sect. 2.1), they incorporate the errors associated with the AERONET inversion algorithm. Dubovik et al. (2000) found that the relative error in the AERONET-retrieved volume size distribution for dust, biomass burning, and water-soluble aerosols can go beyond $50 \%$ for both small $(r<0.1 \mu \mathrm{m})$ and large $(r>7 \mu \mathrm{m})$ particles. In order to account for such errors and natural variability, we analysed the sensitivity of $\mathrm{CCN}$ concentrations to the initial normalized size distributions considered in our retrieval algorithm.
For each aerosol subtype, the initial NVSD can be perturbed by changing the size distribution parameters such as the volume fractions $\left(v_{\mathrm{f}}\right.$ and $\left.v_{\mathrm{c}}\right)$, geometric standard deviations $\left(\sigma_{\mathrm{f}}\right.$ and $\left.\sigma_{\mathrm{c}}\right)$, and mean radii $\left(\mu_{\mathrm{f}}\right.$ and $\left.\mu_{\mathrm{c}}\right)$ of fine and coarse modes. Since the sum of the volume fractions is unity, this leads to five independent size distribution parameters. We first study the individual effects of varying these parameters on the output $n_{j \text {,dry }}(j=100$ for dust and 50 for other aerosol subtypes) as they are the main input to the $\mathrm{CCN}$ parameterizations. Figure 2 depicts the effect of varying these size distribution parameters by $\pm 50 \%$ on the $n_{j \text {,dry }}$ relative 
to that of unperturbed size distributions from CAMel for a preset $\alpha=0.1 \mathrm{~km}^{-1}$ and $\mathrm{RH}=0$ for different aerosol subtypes. The results show fine mode as the primary contributor to the output aerosol number concentration. A certain change in the volume size distribution in the fine mode will have a larger impact on the number concentration compared to the coarse mode as a much larger number of small particles is needed to produce the same change in volume. Out of the five parameters, $\mu_{\mathrm{f}}$ has the maximum effect $(\approx 800 \%)$ on the output number concentration, followed by $\sigma_{\mathrm{f}}(\approx 150 \%)$. This is because both $\mu_{\mathrm{f}}$ and $\sigma_{\mathrm{f}}$ modify the distribution of volume across different radii in the fine mode. Decreasing (increasing) $\mu_{\mathrm{f}}$ shifts the fine mode towards a smaller (larger) radius, thereby resulting in a comparatively larger (smaller) number of particles for a constant fine-mode volume. However, for dust, the effect is opposite when $\mu_{\mathrm{f}}$ is decreased. This is because the minimum cut-off radius for dust is set to be $100 \mathrm{~nm}$, and the fine mode moves out of this limit when $\mu_{\mathrm{f}}$ is reduced, leading to a decrease in the output number concentration. Increasing (decreasing) $\sigma_{\mathrm{f}}$ leads to an increase (decrease) in the fraction of smaller particles within the fine mode. This results in an increase (decrease) in the output number concentration for all aerosol subtypes except dust. The output number concentration is comparatively less sensitive to coarse-mode parameters $\left(\mu_{\mathrm{c}}\right.$ and $\left.\sigma_{\mathrm{c}}\right)$ as they contribute primarily to the optical properties of the aerosol volume rather than the number concentration. When we change the value of $\alpha$, the aerosol number concentration scales as per the ratio between $\alpha$ and $\alpha_{\mathrm{n}}$, resulting in no change in the relative $n_{100, \text { dry }}$ and $n_{50 \text {,dry }}$.

The size distributions formed by varying the size distribution parameters separately may not be sufficient enough to capture the natural variability. Thus to imitate the natural variability in a better way, we further consider combinations of the variations in all the parameters. We do not expect extreme shifts in the size distribution parameters as well. For instance, reducing $\mu_{\mathrm{f}}$ by $50 \%$ results in abnormal size distributions, with $30 \%-50 \%$ of the fine mode moving out of the AERONET size limits $(0.05 \leq r \leq 15 \mu \mathrm{m})$. Therefore, in order to exclude the non-physical size distributions, we limit the variations in the parameters in terms of the actual volume size distributions. To implement these constraints, we first vary the size distribution parameters linearly with a uniform spacing of 0.01 and then consider all possible combinations of the variations. The NVSDs generated from all the combinations form the input NVSD set for the sensitivity analysis. We further fix the maximum limits of bimodal NVSD to $\pm 50 \%$ of the amplitude of each of its modes and do not consider the NVSDs that fall outside this domain in the sensitivity studies. The resulting input NVSD space for each aerosol type is shown by the shaded region of Fig. 3. The maximum and minimum values of all the size distribution parameters considered in the sensitivity analysis are given in Table 2 .

As we have kept a constant spacing for varying the size distribution parameters, the number of NVSDs in the input space directly depends on the volume of particles present in
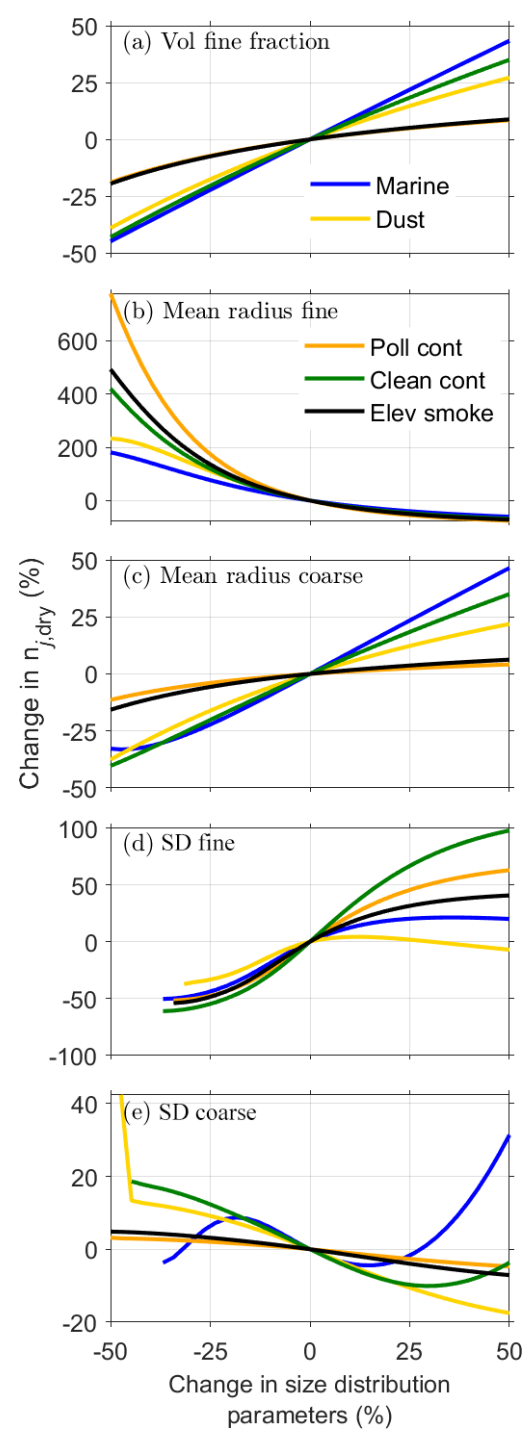

Figure 2. Sensitivity of $n_{j \text {,dry }}(j=100$ for dust and 50 for other aerosol subtypes) to the size distribution parameters: volume fine fraction (a), mean radius fine (b), mean radius coarse (c), standard deviation fine (d), and standard deviation coarse (e). The $x$ axis represents perturbations in the size distribution parameters in percentage of their original values taken from the CALIPSO aerosol model. The $y$ axis represents the corresponding percentage change in $n_{j \text {,dry }}$ relative to that estimated from the unperturbed size distribution.

each mode. While it is minimum for the clean marine subtype because of its almost non-existent fine mode (which reduces the range of variation), it is maximum for polluted continental and elevated smoke subtypes. The output ensembles of number concentrations for an extinction coefficient of $0.1 \mathrm{~km}^{-1}$ and relative humidity of $0 \%$ are shown in the violin plots of Fig. 4 . The percentiles of the output $n_{j, \text { dry }}$ set are given in Table 3. The number concentration of the output ensemble is primarily dependent on the fine mode of the input size distributions. The variations in the output en- 
Table 2. Bimodal log-normal volume size distribution parameters along with their limits considered in the sensitivity analysis. Abbreviations: $\mathrm{VF}$ - volume fraction, MR - mean radius, GSD - geometric standard deviation, CAM - CALIPSO aerosol microphysics.

\begin{tabular}{|c|c|c|c|c|c|c|c|c|c|c|c|c|c|c|c|}
\hline \multirow{3}{*}{$\begin{array}{l}\text { Aerosol } \\
\text { subtype }\end{array}$} & \multicolumn{15}{|c|}{ Size distribution parameters } \\
\hline & \multicolumn{3}{|c|}{ VF fine } & \multicolumn{3}{|c|}{ MR fine } & \multicolumn{3}{|c|}{ MR coarse } & \multicolumn{3}{|c|}{ GSD fine } & \multicolumn{3}{|c|}{ GSD coarse } \\
\hline & CAM & Min & $\operatorname{Max}$ & CAM & Min & $\operatorname{Max}$ & CAM & Min & Max & CAM & Min & Max & CAM & Min & $\operatorname{Max}$ \\
\hline Clean marine & 0.025 & 0.001 & 0.035 & 0.150 & 0.101 & 0.227 & 1.216 & 0.815 & 1.824 & 1.600 & 1.376 & 2.56 & 1.60 & 1.376 & 1.76 \\
\hline Dust & 0.223 & 0.114 & 0.332 & 0.116 & 0.083 & 0.164 & 2.833 & 1.615 & 4.249 & 1.481 & 1.304 & 2.192 & 1.908 & 1.545 & 3.625 \\
\hline Polluted continental & 0.531 & 0.235 & 0.703 & 0.158 & 0.109 & 0.227 & 3.547 & 1.88 & 5.321 & 1.526 & 1.327 & 2.319 & 2.065 & 1.631 & 4.13 \\
\hline Clean continental & 0.050 & 0.001 & 0.069 & 0.206 & 0.136 & 0.310 & 2.633 & 1.501 & 3.950 & 1.61 & 1.385 & 2.592 & 1.899 & 1.538 & 3.589 \\
\hline Elevated smoke & 0.329 & 0.168 & 0.49 & 0.144 & 0.098 & 0.211 & 3.726 & 1.938 & 5.589 & 1.562 & 1.359 & 2.437 & 2.143 & 1.671 & 4.285 \\
\hline
\end{tabular}
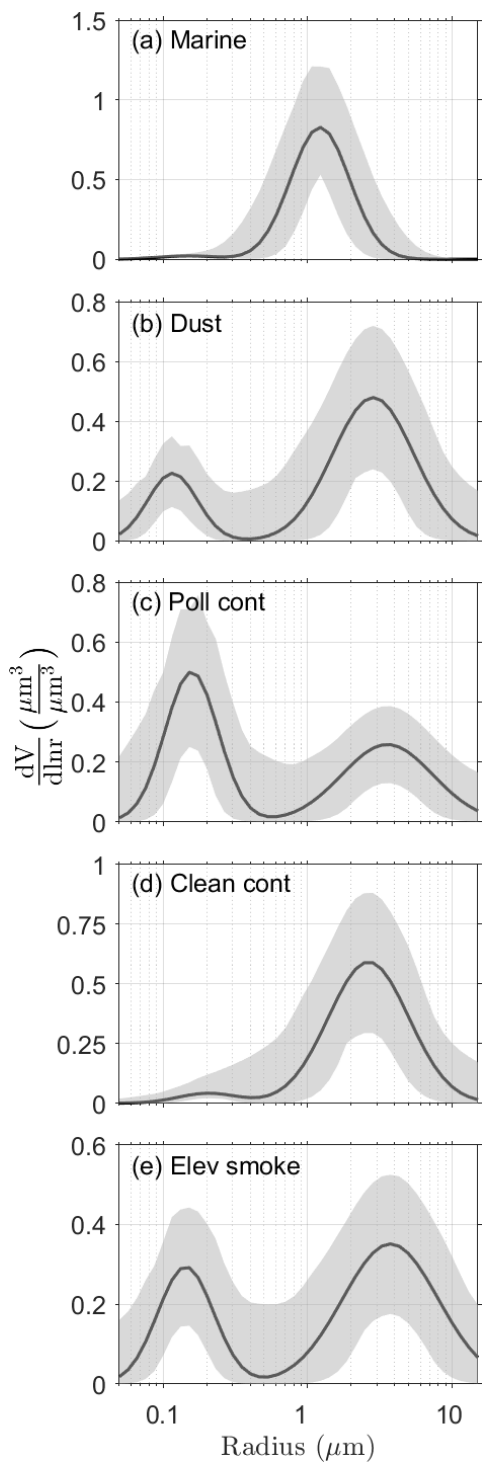

Figure 3. Normalized bimodal log-normal volume size distributions for marine (a), dust (b), polluted continental (c), clean continental (d), and elevated smoke (e) aerosol subtypes adopted from the CALIPSO aerosol model. The shaded region represents the input space along with the maximum and minimum limits of size distributions selected for the sensitivity analysis.
Table 3. Percentiles of output $n_{j, \text { dry }}$ ensembles estimated from the sensitivity analysis relative to that of the unperturbed case.

\begin{tabular}{lrrrr}
\hline \multirow{2}{*}{$\begin{array}{l}\text { Aerosol } \\
\text { subtype }\end{array}$} & \multicolumn{3}{c}{$\begin{array}{c}\text { Percentiles of output } \\
n_{j, \text { dry }} \text { ensembles } \\
\text { relative to unperturbed (\%) }\end{array}$} \\
\cline { 2 - 5 } & 5 th & 25 th & 75 th & 95 th \\
\hline Clean marine & 0.044 & 35.8 & 119.25 & 194.05 \\
Dust & -41.30 & -28.54 & -0.68 & 34 \\
Polluted continental & -56.26 & -20.77 & 88.15 & 259.38 \\
Clean continental & -49.02 & 7.56 & 130.04 & 275 \\
Elevated smoke & -52.23 & -14.16 & 71.68 & 183.55 \\
\hline
\end{tabular}

semble relative to the output from unperturbed NVSD from CAMel is minimum (about a factor of 1) for dust mainly because we only consider particles with a radius $>0.1 \mu \mathrm{m}$. For clean marine, the spread is about a factor of 2 (95th percentile; $200 \%$ ). However, for polluted continental and elevated smoke, the output ensemble is bimodal. For the first mode, the values can go up to a factor of 1.5 for polluted continental and around 1 for elevated smoke. The second mode is relatively small and is related to the size distributions whose fine-mode mean radii are shifted to low values (extreme left in Fig. 2). For this mode, the values can go up to a factor of 3 for polluted continental and 2.5 for elevated smoke. The largest spread in the output ensemble is found for clean continental (95th percentile; factor of 2.7). This might be because the bimodality of the NVSD is not well defined for the clean continental aerosol subtype, thereby increasing the input space of variation. Neglecting the long tail of the distribution, we can assume the uncertainty due to the initial NVSD to be about a factor of 2 .

We have also estimated the effect of change in $\mathrm{RH}$ on the

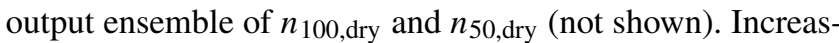
ing RH decreases the spread of the output ensemble slightly, with a significant decrease for $\mathrm{RH}>90 \%$, except for dust, which is assumed to be hydrophobic. At $\mathrm{RH}=99 \%$, the bimodality of polluted continental and elevated smoke subtypes disappears. The variations in the relative number concentrations decrease to less than a factor of 2 for all subtypes. This might be a result of the decrease in the absolute num- 


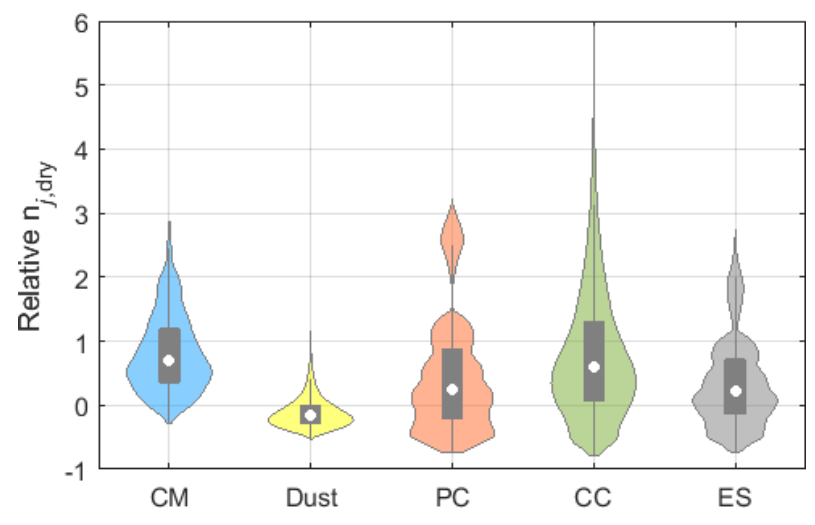

Figure 4. Violin plots for the output ensemble of $n_{j, \text { dry }}(j=100$ for dust and 50 for other aerosol subtypes) relative to that of unperturbed NVSD from the CALIPSO aerosol model. The filled shape shows the probability density of the data (smoothed by nonparametric kernel density estimator) along the $y$ axis, symmetric on either side, representing a violin-like shape. The box limits represent the first and third quartiles, the white circle inside the box is the median, and the ends of the grey line passing through the centre of the box represent the adjacent values (data excluding outliers). Abbreviations: CM - clean marine, $\mathrm{PC}$ - polluted continental, CC - clean continental, and ES - elevated smoke.

ber concentration as the particle size increases with $\mathrm{RH}$, and fewer particles are needed to produce the same extinction. At a constant RH value, when $\alpha$ is modified, the output ensemble of aerosol number concentrations scales as per the ratio between $\alpha$ and $\alpha_{\mathrm{n}}$, resulting in no change in the rel-

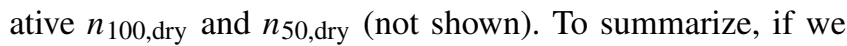
neglect the contributions of extreme shifts in the size distribution (i.e. the long tails in the violin plots) and consider the effect of RH, we can assume that the overall uncertainty in the retrieval algorithm due to the initial NVSD is likely to range between a factor of 1.5 and 2.5 .

Uncertainties in the OMCAM algorithm can also arise from the uncertainty in the CALIPSO measurements, the $\mathrm{CCN}$ parameterization, and the hygroscopicity parameterization. The CALIPSO-retrieved extinction coefficient can have an uncertainty of up to $30 \%$ (Omar et al., 2009; Kim et al., 2018). The ability of aerosol to act as CCN depends on the composition, size, and atmospheric supersaturation value. In situations with complex aerosol mixtures and variable updraught velocity, the simple $\mathrm{CCN}$ parameterization developed by Mamouri and Ansmann (2016) may fail. The $\kappa$ values used to account for the hygroscopicity are global averages and may vary regionally depending on the aerosol source, composition, and age. Moreover, the hydrophobic approximation for dust may not work for cases in which dust is coated or mixed with soluble aerosols (Mamouri and Ansmann, 2016). In such a case, dust aerosols with a dry radius $>50 \mathrm{~nm}$ can also act as $\mathrm{CCN}$ (Mamouri and Ansmann, 2016). Furthermore, aerosol misclassification in the CALIPSO aerosol-typing scheme (Ansmann et al., 2021a) may introduce errors in the OMCAM algorithm. Accounting for the mentioned possibilities, we assume that the overall uncertainty in our retrieval algorithm is likely to range between a factor of 2 and 3. It is comparable to the uncertainty in POLIPHON retrieval. However, OMCAM incorporates additional uncertainties due to the hygroscopicity correction. Studies have found that the conversion factors used in the POLIPHON technique for dust and smoke aerosols vary with the source region and the age of aerosols (Ansmann et al., 2019, 2021b). Such factors further increase the uncertainties associated with the retrieval algorithm when applied to satellite or global data sets.

\subsection{Comparison with POLIPHON}

In this section, we present a theoretical comparison of the CCN concentrations estimated using the OMCAM and POLIPHON methods (Mamouri and Ansmann, 2016). Both algorithms' primary input is the aerosol-type-specific extinction coefficient. Hence, we consider a range of extinction coefficients and compute the corresponding theoretical CCN concentrations with both algorithms. To estimate $\mathrm{CCN}$ concentrations with POLIPHON, we use the extinction-to-CCN conversions given in Eq. (1). The ratio between the CCN concentrations estimated using POLIPHON (CCN $\left.\mathrm{COLI}_{\mathrm{PO}}\right)$ and OMCAM ( $\left.\mathrm{CCN}_{\mathrm{OMCAM}}\right)$ algorithms for varying extinction coefficients at a supersaturation of $0.15 \%$ and zero relative humidity is shown in Fig. 5. The continental aerosols in POLIPHON represent a mixture of urban haze, biomass burning, road dust, and biological particles (Mamouri and Ansmann, 2016). Thus we compare it with the polluted continental aerosol subtype of CALIPSO. For continental aerosols, $\mathrm{CCN}_{\mathrm{POLI}}$ and $\mathrm{CCN}_{\mathrm{OMCAM}}$ are comparable, with the former always being larger than the latter. For smoke aerosols, both the algorithms yield similar values for $\alpha>$ $0.05 \mathrm{~km}^{-1}$. For $\alpha<0.05 \mathrm{~km}^{-1}$, the POLIPHON values can be up to 2 times larger than those of OMCAM. The CCN concentrations estimated from both the algorithms yield similar results for dust as well, with comparable values for $\alpha>0.1 \mathrm{~km}^{-1}$ and increasing disparity for decreasing $\alpha$ below $0.05 \mathrm{~km}^{-1}$. In the derivation of the conversion factors and extinction exponents in the POLIPHON method by regression analysis, the sample size for AOD $<0.05$ is either zero for dust (Ansmann et al., 2019) or limited for smoke aerosols (Ansmann et al., 2021b). It might be a reason behind the difference between the $\mathrm{CCN}_{\text {POLI }}$ and $\mathrm{CCN}_{\text {OMCAM }}$ for smoke and dust aerosols for $\alpha<0.05 \mathrm{~km}^{-1}$. However, for the case of marine aerosols, the values estimated using POLIPHON are significantly larger than those of OMCAM (up to 6 times). This may be due to the different approaches followed and sample sizes considered to derive the size distributions used in the two algorithms. The POLIPHON conversion factor for marine aerosol is estimated from 7.5 years of measurements between 2007 and 2015 at the Barbados AERONET site (Mamouri and Ansmann, 2016). In contrast, 


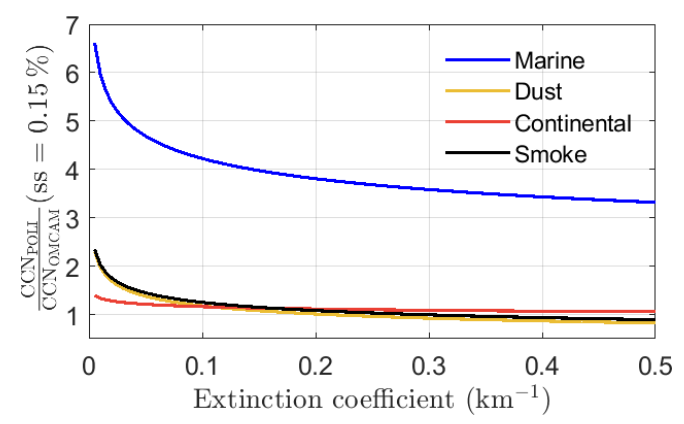

Figure 5. Ratio of $\mathrm{CCN}_{\mathrm{ss}=0.15}$ estimated from POLIPHON and OMCAM algorithms for varying extinction coefficient for marine, dust, continental, and smoke aerosol subtypes.

the marine model used in OMCAM is derived from in situ measurements of sea-salt size distributions produced from breaking waves, taken during the SEAS experiment at Bellows Air Force Station, Oahu, Hawaii, between 21 and 30 April 2000 (Masonis et al., 2003; Clarke et al., 2003). Studies found that the AERONET size distributions can be significantly different from the in situ measurements - especially under high-relative-humidity conditions (Chauvigné et al., 2016; Schafer et al., 2019). Further studies involving typespecific comparisons of both the aerosol number concentrations and the $\mathrm{CCN}$ concentrations with in situ measurements are required to test the reliability of both algorithms (Mamali et al., 2018). When it comes to ease of application, the POLIPHON method with its simple extinction-to-CCN conversion is more straightforward, while the OMCAM algorithm - at the present stage - is more complex and computationally expensive. Despite the complexities, OMCAM incorporates a hygroscopicity correction methodology which is essential for a CALIPSO-based CCN retrieval (Georgoulias et al., 2020). Furthermore, the computation time in the OMCAM algorithm can be drastically reduced by either (i) parameterizing the output $\mathrm{CCN}$ concentrations in terms of the type-specific extinction coefficient and $\mathrm{RH}$ values or (ii) creating a look-up table of $\mathrm{CCN}$ concentrations at different extinction coefficients and RH values for different aerosol subtypes. However, such developments are not within the scope of the present work, which focuses on the theoretical description of the OMCAM algorithm.

\subsection{Case study}

In this section, we compare the profiles of aerosol number concentrations derived using the OMCAM and POLIPHON algorithms with the in situ observations taken during the ACEMED-EUFAR campaign (evaluation of CALIPSO's aerosol classification scheme over the eastern Mediterranean). Specifically, we use the $n_{50 \text {,dry }}$ concentrations estimated from the in situ measurements taken on 9 September 2011 at 00:05-01:50 UTC over land and sea surface around Thessaloniki given in Tsekeri et al. (2017, Tables 3 and 5) (hereafter referred to as T17). The airborne in situ measurements coincide in space and time with the CALIPSO nighttime overpass at 00:40 UTC over Thessaloniki. Georgoulias et al. (2020) (hereafter written as G20) applied the POLIPHON method to the overlapping CALIPSO measurements and estimated the $\mathrm{CCN}$ concentrations at a supersaturation of $0.15 \%$ ( $n_{100 \text {,dry }}$ for dust and $n_{50 \text {,dry }}$ for continental and marine aerosols) for comparison with the in situ measurements from T17. We apply the OMCAM algorithm to the same CALIPSO overpass and compute the $n_{50 \text {,dry }}$ concentrations. The results are discussed in the following.

The profiles of CALIPSO-measured extinction coefficient, aerosol subtype, and the $n_{50 \text {,dry }}$ concentration calculated from the OMCAM algorithm for the CALIPSO overpass over Thessaloniki on 9 September 2011 are shown in Fig. 6. Over the land areas (latitude from $40.6-41.2^{\circ} \mathrm{N}$ ), the CALIPSO aerosol typing algorithm identifies the presence of elevated smoke and polluted continental aerosols (Fig. 6b). However, for retrieving the extinction coefficient for polluted continental aerosol layer, the lidar ratio was modified and, thus, is not considered in our present comparison (not shown). The presence of smoke over the land region was also identified by T17. The CALIPSO-measured extinction coefficient over land is highly variable in space, ranging from 0.07 to as high as $\approx 3 \mathrm{~km}^{-1}$ in the proximity of cloud. The OMCAM-estimated $n_{50 \text {,dry }}$ correspondingly varies from 617 to $40000 \mathrm{~cm}^{-3}$. Over the sea region (latitude from $40-40.6^{\circ} \mathrm{N}$ ), $\mathrm{T} 17$ detected the presence of elevated smoke plumes. This was not detected by the aerosol typing algorithm of earlier version 3 CALIPSO data used in T17. However, with the modifications of version 4 used in this work, CALIPSO successfully detects elevated smoke, marine, and dust aerosols, with elevated smoke being the dominant one. The overall extinction coefficient along with its variability over the sea area is lower compared to land, with the values ranging from 0.026 to $0.36 \mathrm{~km}^{-1}$. The corresponding OMCAM-estimated $n_{50 \text {,dry }}$ concentrations vary from 33 to $5000 \mathrm{~cm}^{-3}$.

T17 estimated the $n_{50 \text {,dry }}$ at different altitudes over the land region corresponding to two $5 \mathrm{~km}$ cloud-free segments of CALIPSO retrieval with latitudes between 40.85 and $40.95^{\circ} \mathrm{N}$. The average $n_{50 \text {,dry }}$ concentration estimated for the selected CALIPSO segments over land using OMCAM and POLIPHON (taken from G20) is plotted along with the in situ measurements from T17 in Fig. 7a, and the values are listed in Table 4. On average, when no hygroscopicity correction is applied, the OMCAM and POLIPHON overestimate the $n_{50 \text {,dry }}$ concentration by $355 \%$ and $370 \%$, respectively. A similar result from OMCAM and POLIPHON is expected given that elevated smoke was the dominant aerosol type over the land with extinction coefficient $>0.1 \mathrm{~km}^{-1}$, for which both the algorithms yield a similar result (Fig. 5). Upon accounting for the hygroscopic growth, the overestimation decreases to $167 \%$ (130\% for POLIPHON). Note that the $\mathrm{RH}$-corrected POLIPHON values in G20 are produced by 

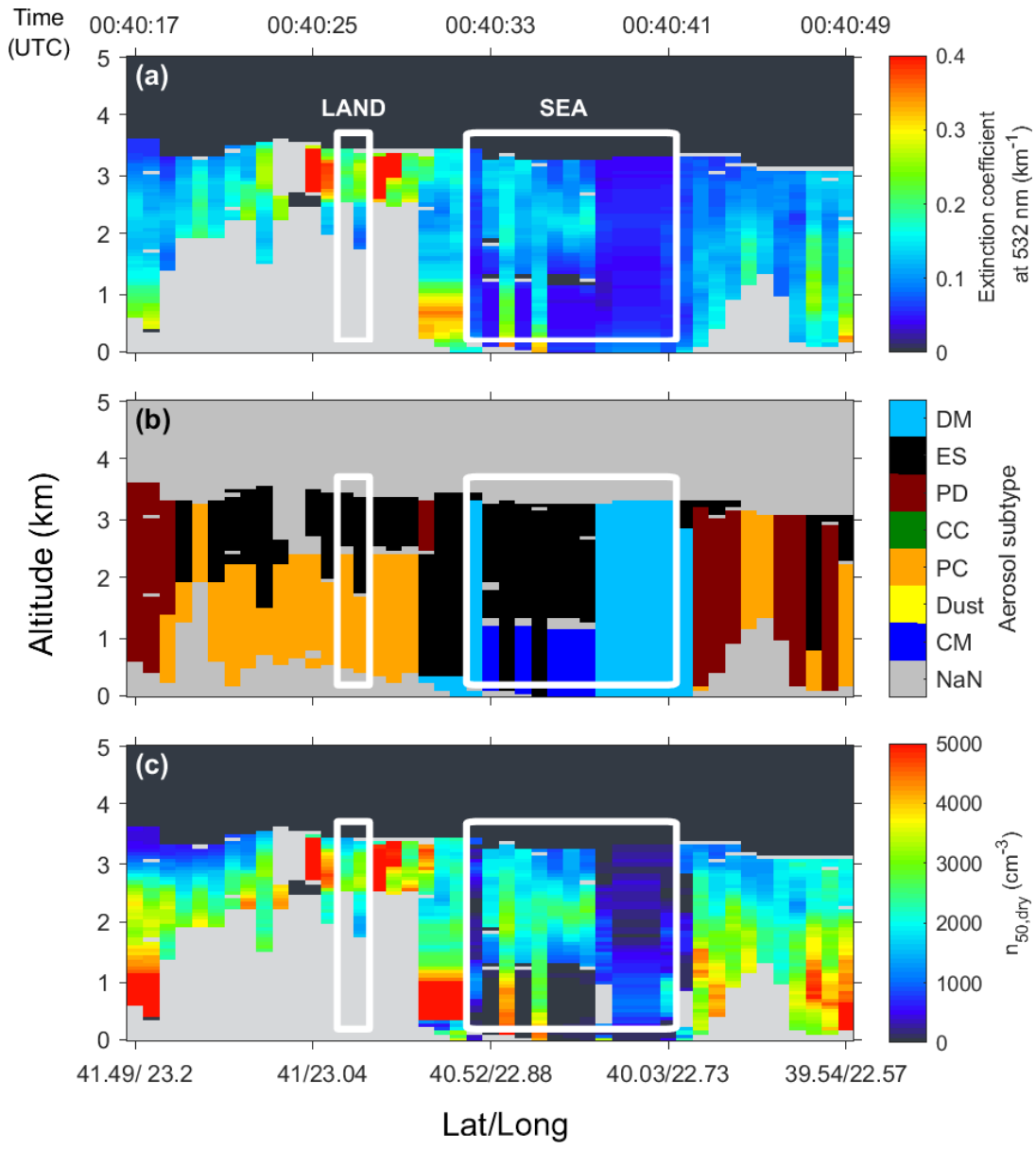

Figure 6. Plot of extinction coefficient (a), aerosol subtype mask (b), and the OMCAM-estimated $n_{50 \text {,dry }}$ concentrations (c) for a CALIPSO overpass over the Thessaloniki region of northern Greece on 9 September 2011. The white lines mark the land $\left(40.85-40.95^{\circ} \mathrm{N}\right)$ and sea $\left(40-40.6^{\circ} \mathrm{N}\right)$ regions for which the in situ observations at different altitudes are provided by Tsekeri et al. (2017). The grey colour represents invalid values $(\mathrm{NaN})$. Abbreviations: $\mathrm{CM}$ - clean marine, $\mathrm{PC}$ - polluted continental, $\mathrm{CC}$ - clean continental, PD - polluted dust, ES - elevated smoke, and DM - dusty marine.

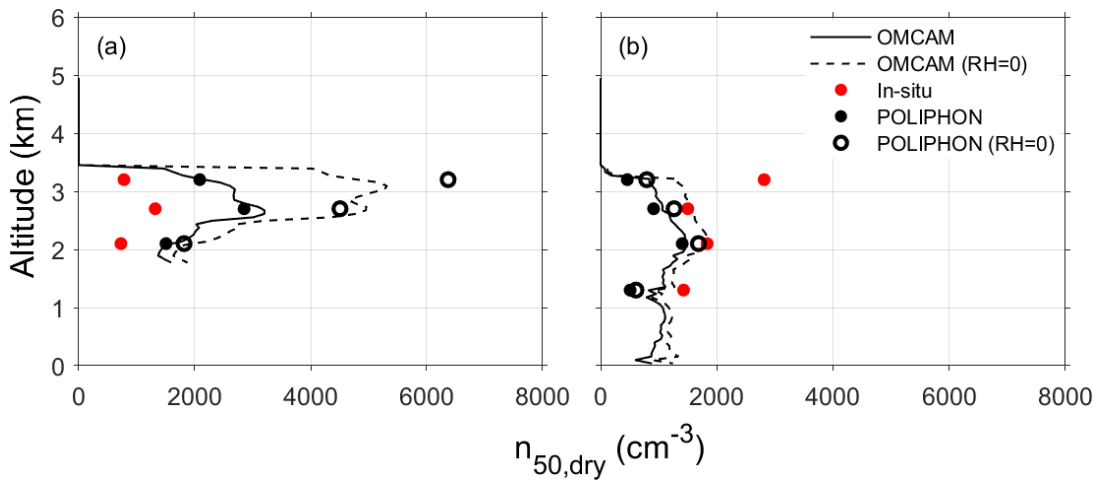

Figure 7. The $n_{50, \text { dry }}$ concentrations estimated from CALIPSO satellite data using OMCAM (solid line) and POLIPHON (black dots) incorporated from Georgoulias et al. (2020) and in situ aircraft observations (red dots) adopted from Tsekeri et al. (2017) over the land (a) and sea (b) surface close to the Thessaloniki region. The dotted line and unfilled black circles represent the $n_{50 \text {,dry }}$ estimated from OMCAM and POLIPHON, respectively, when hygroscopicity correction is not considered. 
Table 4. The $n_{50 \text {,dry }}$ concentrations (in $\mathrm{cm}^{-3}$ ) from in situ measurements (Tsekeri et al., 2017) and CALIPSO measurements by using OMCAM and POLIPHON (Georgoulias et al., 2020) algorithms at different altitudes over land and sea regions around Thessaloniki, Greece. The values inside the brackets refers to zero-humidity case (no hygroscopicity correction applied).

\begin{tabular}{lrrrrrr}
\hline Region & Altitude & In situ & OMCAM & POLIPHON & \multicolumn{2}{c}{ CALIPSO - in situ (\%) } \\
\cline { 6 - 6 } & & & $(\mathrm{RH}=0)$ & $(\mathrm{RH}=0)$ & OMCAM (RH =0) & POLIPHON (RH = 0) \\
\hline \multirow{2}{*}{ Land } & 2.1 & 727 & $1590(1957)$ & $1504(1816)$ & $119(169)$ & $107(150)$ \\
& 2.7 & 1318 & $3171(5296)$ & $2851(4505)$ & $141(302)$ & $116(242)$ \\
& 3.2 & 779 & $2160(5401)$ & $2086(6370)$ & $177(593)$ & $168(718)$ \\
\hline \multirow{2}{*}{ Sea } & 1.3 & 1427 & $826(926)$ & $508(609)$ & $-42(-35)$ & $-64(-57)$ \\
& 2.1 & 1834 & $1476(1796)$ & $1405(1683)$ & $-20(-2)$ & $-23(-8)$ \\
& 2.7 & 1601 & $1065(1504)$ & $912(1264)$ & $-29(0)$ & $-89(-16)$ \\
& 3.2 & 2814 & $841(1357)$ & $459(794)$ & $-70(-52)$ & $-84(-72)$ \\
\hline
\end{tabular}

using the in situ dry to ambient extinction coefficient ratios (DARs) measured at different RH values during the aircraft measurements (Tsekeri et al., 2017). In contrast to the overestimation over the land, both the algorithms underestimate the $n_{50 \text {,dry }}$ concentrations over the sea (Fig. 7b). When we do not account for the hygroscopic growth, both the OMCAM and POLIPHON algorithms underestimate the $n_{50 \text {,dry }}$ concentration by $22 \%$ and $38 \%$, respectively. When the RH growth is corrected, the underestimation further increases to $40 \%$ and $52 \%$, respectively. Similar to land regions, both the algorithms yield comparable results over the sea as the dominant aerosol type is elevated smoke in both scenarios.

The $n_{50 \text {,dry }}$ values estimated over the land and sea region from the OMCAM and POLIPHON algorithms are comparable to each other. The RH-corrected POLIPHON values (using in situ DAR measurements) are in good agreement with those of OMCAM, which uses kappa parameterization with globally averaged kappa values. Both the OMCAM and POLIPHON algorithms were able to capture the pattern of altitudinal variations in $n_{50 \text {,dry }}$ as observed by the in situ measurements. However, the magnitudes of $n_{50 \text {,dry }}$ are overestimated by both the algorithms over the land by a factor of 1.5 , whereas over the sea region, the underestimation by both the algorithms is about a factor of 0.5. One of the intrinsic limitations of this comparison results from the vast difference in measuring timescales of CALIPSO and the research aircraft. While for CALIPSO it is as small as $15 \mathrm{~s}$, it is around $2 \mathrm{~h}$ for the aircraft. From Fig. $6 \mathrm{c}$, we can clearly see that the extinction coefficient along with the $n_{50, \text { dry }}$ concentrations is highly variable over the land region (ranging from 617 to $40000 \mathrm{~cm}^{-3}$ ) compared to rather homogeneous concentrations over the sea. This might be the reason for the large discrepancy between in situ and CALIPSO retrievals over the land region. Moreover, only two cloud-free CALIPSO $5 \mathrm{~km}$ profiles are considered for the comparison over land, which further increases the chances of disparity. Given the limited sample space, this comparison should not be considered to be validation but rather a demonstration of the capability for re- trieving $\mathrm{CCN}$ concentrations from spaceborne lidar measurements. A detailed study comparing the CALIPSO-retrieved aerosol number and CCN concentrations with ground-based and aircraft in situ measurements is required to evaluate the reliability of OMCAM and POLIPHON algorithms in estimating the $\mathrm{CCN}$ concentrations.

\section{Summary and conclusions}

We present the OMCAM algorithm to derive the heightresolved cloud-relevant $\mathrm{CCN}$ concentrations from CALIPSO measurements. The algorithm uses the normalized size distributions and refractive indices from CALIPSO aerosol models (Omar et al., 2009) as an input to MOPSMAP to calculate the extinction coefficient. The size distributions are then scaled to reproduce the CALIPSO-measured extinction coefficient. To account for the hygroscopicity, we use kappa parameterization (Petters and Kreidenweis, 2007) and modify the size distribution and the refractive index before the scaling step. We then estimate the required aerosol number concentration by integrating the final scaled size distributions over the size ranges relevant for different aerosol types. Utilizing the aerosol-type-specific CCN parameterizations from Mamouri and Ansmann (2016), we convert the aerosol number concentrations to cloud-relevant $\mathrm{CCN}$ concentrations for different supersaturation.

The OMCAM algorithm relies on the potentiality of the CALIPSO aerosol models to accurately describe the microphysical properties of the aerosol subtypes defined within the CALIPSO retrieval algorithm. We performed sensitivity tests by varying the normalized size distributions by up to $\pm 50 \%$ of the amplitude of each mode and found that the uncertainty in the final aerosol number concentration ranges between a factor of 2 and 3.

We compared the $\mathrm{CCN}$ concentrations obtained from OMCAM with those of the POLIPHON method - the existing method for lidar-based CCN retrieval. For extinction coefficients $>0.05 \mathrm{~km}^{-1}$, we found a good agreement for con- 
tinental, dust, and smoke aerosols. However, as the extinction coefficient becomes smaller than $0.05 \mathrm{~km}^{-1}$, the difference increases, with the POLIPHON values going as high as twice the OMCAM values. For marine aerosols, the CCN concentration derived using the POLIPHON method is always higher (4-6 times) than that of OMCAM.

For an initial evaluation of the OMCAM algorithm, we compared the thus obtained $n_{50 \text {,dry }}$ with in situ measurements taken over the land and sea region around Thessaloniki during the ACEMED campaign (Tsekeri et al., 2017). For the retrievals over sea, we found that CALIPSO underestimates the $n_{50 \text {,dry }}$ by about $40 \%$. Over the land areas; however, CALIPSO overestimates $n_{50 \text {,dry }}$ by about $167 \%$. The large discrepancies may be a result of the combination of highly variable $n_{50 \text {,dry }}$ over the land region and the instantaneous measurement by CALIPSO in contrast to the in situ measurement, which was performed in a time period of $2 \mathrm{~h}$. All values remained within a factor of 2 , which is in agreement with the estimated uncertainty. Moreover, the $n_{50 \text {,dry }}$ retrieved from CALIPSO using the OMCAM algorithm was comparable to that of POLIPHON (Georgoulias et al., 2020).

Our future goals include a comprehensive evaluation of the CALIPSO-derived aerosol number and CCN concentrations with ground-based and airborne in situ measurements. We will use the airborne Atmospheric Tomography Mission measurements of aerosol number concentration profiles from altitudes of 0.2 to $12 \mathrm{~km}$ between the years 2016 and 2018 (Williamson et al., 2019) to access the quality of the respective parameter derived from CALIPSO. Furthermore, we will also compare the CALIPSO products with the long-term surface measurements of $\mathrm{CCN}$ and aerosol size distributions from 11 atmospheric observatories around the globe between 2006 and 2016 (Schmale et al., 2017). The comparison study will enable us to test the applicability of OMCAM and POLIPHON algorithms in the context of estimating the aerosol number and $\mathrm{CCN}$ concentrations from spaceborne lidar measurements. Ultimately, we plan to apply the best-performing algorithm to more than 15 years of CALIPSO data to construct a global height-resolved CCN climatology. The data set when coupled with other satellitebased global cloud-related data or state-of-the-art numerical models will help in improving our current understanding of the aerosol-cloud interactions. Also, it will be interesting to compare the CALIPSO-derived $\mathrm{CCN}$ concentrations with emerging aerosol remote sensing techniques available for other satellites. For instance, Rosenfeld et al. (2016) formulated an algorithm for estimating $\mathrm{CCN}$ concentrations from the measurements of the Visible/Infrared Imager Radiometer Suite (VIIRS) instrument aboard the Suomi National Polar-orbiting Partnership (NPP) satellite by treating clouds as CCN chambers for convective clouds and later on extended the algorithm for marine stratocumulus clouds (Efraim et al., 2020).

The ability of CALIPSO not only to measure vertically resolved aerosol optical properties but also to detect the respon- sible aerosol type has facilitated the retrieval of global 3D type-specific aerosol properties. We have described a novel methodology to retrieve cloud-relevant $\mathrm{CCN}$ concentrations from CALIPSO measurements, illustrating the potential of CALIPSO to produce 3D global CCN climatology for ACI studies and climate model evaluations, opening new gates for further validation of the algorithm against ground-based and airborne in situ measurements.

Data availability. The CALIPSO level 2 v4.20 aerosol profile data product used in this work is available at https://doi.org/10.5067/CALIOP/CALIPSO/LID_L2_05KMAPROSTANDARD-V4-20 (CALIPSO, 2018).

Author contributions. MT conceptualized the study. GC developed the methodology under the guidance of MT. GC performed the data analysis and prepared the plots. GC and MT contributed equally to the interpretation of the data as well as to the preparation and revision of the manuscript.

Competing interests. The contact author has declared that neither they nor their co-authors have any competing interests.

Disclaimer. Publisher's note: Copernicus Publications remains neutral with regard to jurisdictional claims in published maps and institutional affiliations.

Acknowledgements. We are grateful to Josef Gasteiger (University of Vienna, Vienna, Austria) for his help in compiling the MOPSMAP package. We are thankful to Albert Ansmann (Leibniz Institute for Tropospheric Research, Leipzig, Germany) for fruitful discussion on the overall algorithm. We thank the CALIPSO science team for providing the CALIPSO data. We thank the AERIS/ICARE Data and Services Center for providing access to the CALIPSO data used in this study.

Financial support. This research has been supported by the Franco-German Fellowship Programme on Climate, Energy, and Earth System Research (Make Our Planet Great Again - German Research Initiative, MOPGA-GRI, grant no. 57429422) of the German Academic Exchange Service (DAAD), funded by the German Ministry of Education and Research.

Review statement. This paper was edited by Otto Hasekamp and reviewed by Aristeidis Georgoulias and one anonymous referee. 


\section{References}

Anderson, T. L., Masonis, S. J., Covert, D. S., Charlson, R. J., and Rood, M. J.: In situ measurement of the aerosol extinction-to-backscatter ratio at a polluted continental site, J. Geophys. Res.-Atmos., 105, 26907-26915, https://doi.org/10.1029/2000JD900400, 2000.

Andreae, M. O. and Rosenfeld, D.: Aerosol-cloudprecipitation interactions. Part 1 . The nature and sources of cloud-active aerosols, Earth-Sci. Rev., 89, 13-41, https://doi.org/10.1016/j.earscirev.2008.03.001, 2008.

Ansmann, A., Mamouri, R.-E., Hofer, J., Baars, H., Althausen, D., and Abdullaev, S. F.: Dust mass, cloud condensation nuclei, and ice-nucleating particle profiling with polarization lidar: updated POLIPHON conversion factors from global AERONET analysis, Atmos. Meas. Tech., 12, 4849-4865, https://doi.org/10.5194/amt-12-4849-2019, 2019.

Ansmann, A., Ohneiser, K., Chudnovsky, A., Baars, H., and Engelmann, R.: CALIPSO Aerosol-Typing Scheme Misclassified Stratospheric Fire Smoke: Case Study From the 2019 Siberian Wildfire Season, Front. Environ. Sci., 9, 769852, https://doi.org/10.3389/fenvs.2021.769852, 2021a.

Ansmann, A., Ohneiser, K., Mamouri, R.-E., Knopf, D. A., Veselovskii, I., Baars, H., Engelmann, R., Foth, A., Jimenez, C., Seifert, P., and Barja, B.: Tropospheric and stratospheric wildfire smoke profiling with lidar: mass, surface area, $\mathrm{CCN}$, and INP retrieval, Atmos. Chem. Phys., 21, 9779-9807, https://doi.org/10.5194/acp-21-9779-2021, 2021b.

CALIPSO: Cloud-Aerosol Lidar and Infrared Pathfinder Satellite Observation Lidar Level 2 Aerosol Profile, V4-20, NASA Langley Atmospheric Science Data Center DAAC [data set], https://doi.org/10.5067/CALIOP/CALIPSO/LID_L2_ 05KMAPRO-STANDARD-V4-20, 2018.

Chauvigné, A., Sellegri, K., Hervo, M., Montoux, N., Freville, P., and Goloub, P.: Comparison of the aerosol optical properties and size distribution retrieved by sun photometer with in situ measurements at midlatitude, Atmos. Meas. Tech., 9, 4569-4585, https://doi.org/10.5194/amt-9-4569-2016, 2016.

Chen-Chen, H., Perez-Hoyos, S., and Sánchez-Lavega, A.: Dust particle size, shape and optical depth during the 2018/my34 Martian global dust storm retrieved by MSL curiosity rover navigation cameras, Icarus, 354, 114021, https://doi.org/10.1016/j.icarus.2020.114021, 2021.

Choudhury, G., Tyagi, B., Singh, J., Sarangi, C., and Tripathi, S. N.: Aerosol-orography-precipitation-A critical assessment, Atmos. Environ., 214, 116831, https://doi.org/10.1016/j.atmosenv.2019.116831, 2019.

Choudhury, G., Tyagi, B., Vissa, N. K., Singh, J., Sarangi, C., Tripathi, S. N., and Tesche, M.: Aerosol-enhanced high precipitation events near the Himalayan foothills, Atmos. Chem. Phys., 20, 15389-15399, https://doi.org/10.5194/acp-20-153892020, 2020.

Clarke, A., Kapustin, V., Howell, S., Moore, K., Lienert, B., Masonis, S., Anderson, T., and Covert, D.: Sea-salt size distributions from breaking waves: Implications for marine aerosol production and optical extinction measurements during SEAS, J. Atmos. Ocean. Tech., 20, 1362-1374, https://doi.org/10.1175/15200426(2003)020<1362:SSDFBW>2.0.CO;2, 2003.

Costantino, L. and Bréon, F.-M.: Aerosol indirect effect on warm clouds over South-East Atlantic, from co-located MODIS and CALIPSO observations, Atmos. Chem. Phys., 13, 69-88, https://doi.org/10.5194/acp-13-69-2013, 2013.

DeMott, P. J., Prenni, A. J., Liu, X., Kreidenweis, S. M., Petters, M. D., Twohy, C. H., Richardson, M. S., Eidhammer, T., and Rogers, D. C.: Predicting global atmospheric ice nuclei distributions and their impacts on climate, P. Natl. Acad. Sci. USA, 107, 1121711222, https://doi.org/10.1073/pnas.0910818107, 2010.

DeMott, P. J., Prenni, A. J., McMeeking, G. R., Sullivan, R. C., Petters, M. D., Tobo, Y., Niemand, M., Möhler, O., Snider, J. R., Wang, Z., and Kreidenweis, S. M.: Integrating laboratory and field data to quantify the immersion freezing ice nucleation activity of mineral dust particles, Atmos. Chem. Phys., 15, 393-409, https://doi.org/10.5194/acp-15-393-2015, 2015.

Douglas, A. and L'Ecuyer, T.: Quantifying variations in shortwave aerosol-cloud-radiation interactions using local meteorology and cloud state constraints, Atmos. Chem. Phys., 19, 62516268, https://doi.org/10.5194/acp-19-6251-2019, 2019.

Dubovik, O., Smirnov, A., Holben, B. N., King, M. D., Kaufman, Y. J., Eck, T. F., and Slutsker, I.: Accuracy assessments of aerosol optical properties retrieved from Aerosol Robotic Network (AERONET) Sun and sky radiance measurements, J. Geophys. Res.-Atmos., 105, 9791-9806, https://doi.org/10.1029/2000JD900040, 2000.

Dubovik, O., Sinyuk, A., Lapyonok, T., Holben, B. N., Mishchenko, M., Yang, P., Eck, T. F., Volten, H., Munoz, O., Veihelmann, B., and Van der Zande, W. J.: Application of spheroid models to account for aerosol particle nonsphericity in remote sensing of desert dust, J. Geophys. Res.-Atmos., 111, D11208, https://doi.org/10.1029/2005JD006619, 2006.

Dubovik, O., Fuertes, D., Litvinov, P., Lopatin, A., Lapyonok, T., Doubovik, I., Xu, F., Ducos, F., Chen, C., Torres, B., Derimian, Y., Li, L., Herreras-Giralda, M., Herrera, M., Karol, Y., Matar, C., Schuster, G. L., Espinosa, R., Puthukkudy, A., Li, Z., Fischer, J., Preusker, R., Cuesta, J., Kreuter, A., Cede, A., Aspetsberger, M., Marth, D., Bindreiter, L., Hangler, A., Lanzinger, V., Holter, C., and Federspiel, C.: A Comprehensive Description of Multi-Term LSM for Applying Multiple a Priori Constraints in Problems of Atmospheric Remote Sensing: GRASP Algorithm, Concept, and Applications, Front. Remote Sens., 2, 706851, https://doi.org/10.3389/frsen.2021.706851, 2021.

Dusek, U., Frank, G. P., Hildebrandt, L., Curtius, J., Schneider, J., Walter, S., Chand, D., Drewnick, F., Hings, S., Jung, D., and Borrmann, S.: Size matters more than chemistry for cloudnucleating ability of aerosol particles, Science, 312, 1375-1378, https://doi.org/10.1126/science.1125261, 2006.

Efraim, A., Rosenfeld, D., Schmale, J., and Zhu, Y.: Satellite retrieval of cloud condensation nuclei concentrations in marine stratocumulus by using clouds as CCN chambers, J. Geophys. Res.-Atmos., 125, e2020JD032409, https://doi.org/10.1029/2020JD032409, 2020.

Fan, J., Wang, Y., Rosenfeld, D., and Liu, X.: Review of aerosolcloud interactions: Mechanisms, significance, and challenges, J. Atmos. Sci., 73, 4221-4252, https://doi.org/10.1175/JAS-D-160037.1, 2016.

Gasteiger, J. and Wiegner, M.: MOPSMAP v1.0: a versatile tool for the modeling of aerosol optical properties, Geosci. Model Dev., 11, 2739-2762, https://doi.org/10.5194/gmd-112739-2018, 2018. 
Georgoulias, A. K., Marinou, E., Tsekeri, A., Proestakis, E., Akritidis, D., Alexandri, G., Zanis, P., Balis, D., Marenco, F., Tesche, M., and Amiridis, V.: A first case study of CCN concentrations from spaceborne lidar observations, Remote Sens., 12, 1557, https://doi.org/10.3390/rs12101557, 2020.

Gryspeerdt, E. and Stier, P.: Regime-based analysis of aerosolcloud interactions, Geophys. Res. Lett., 39, L21802, https://doi.org/10.1029/2012GL053221, 2012.

Gryspeerdt, E., Quaas, J., Ferrachat, S., Gettelman, A., Ghan, S., Lohmann, U., Morrison, H., Neubauer, D., Partridge, D. G., Stier, P., and Takemura, T.: Constraining the instantaneous aerosol influence on cloud albedo, P. Natl. Acad. Sci. USA, 114, 48994904, https://doi.org/10.1073/pnas.1617765114, 2017.

Hasekamp, O. P., Gryspeerdt, E., and Quaas, J.: Analysis of polarimetric satellite measurements suggests stronger cooling due to aerosol-cloud interactions, Nat. Commun., 10, 1-7, https://doi.org/10.1038/s41467-019-13372-2, 2019.

IPCC: Climate Change 2021: The Physical Science Basis. Contribution of Working Group I to the Sixth Assessment Report of the Intergovernmental Panel on Climate Change, edited by: Masson-Delmotte, V., Zhai, P., Pirani, A., Connors, S. L., Péan, C., Berger, S., Caud, N., Chen, Y., Goldfarb, L., Gomis, M. I., Huang, M., Leitzell, K., Lonnoy, E., Matthews, J. B. R., Maycock, T. K., Waterfield, T., Yelekçi, O., Yu, R., and Zhou, B., Cambridge University Press, in press, available at: https:// www.ipcc.ch/report/ar6/wg1/\#FullReport, last access: 5 December 2021.

Jia, H., Ma, X., Yu, F., and Quaas, J.: Significant underestimation of radiative forcing by aerosol-cloud interactions derived from satellite-based methods, Nat. Commun., 12, 3649, https://doi.org/10.1038/s41467-021-23888-1, 2021.

Jiang, M., Liu, X., Han, J., Wang, Z., and Xu, M.: Influence of particle properties on measuring a low-particulate-mass concentration by light extinction method, Fuel, 286, 119460, https://doi.org/10.1016/j.fuel.2020.119460, 2021.

Kalashnikova, O. V. and Sokolik, I. N.: Importance of shapes and compositions of wind-blown dust particles for remote sensing at solar wavelengths, Geophys. Res. Lett., 29, 1398, https://doi.org/10.1029/2002GL014947, 2002.

Kant, S., Panda, J., Pani, S. K., and Wang, P. K.: Longterm study of aerosol-cloud-precipitation interaction over the eastern part of India using satellite observations during pre-monsoon season, Theor. Appl. Climatol., 136, 605-626, https://doi.org/10.1007/s00704-018-2509-2, 2019.

Kim, M.-H., Omar, A. H., Tackett, J. L., Vaughan, M. A., Winker, D. M., Trepte, C. R., Hu, Y., Liu, Z., Poole, L. R., Pitts, M. C., Kar, J., and Magill, B. E.: The CALIPSO version 4 automated aerosol classification and lidar ratio selection algorithm, Atmos. Meas. Tech., 11, 6107-6135, https://doi.org/10.5194/amt11-6107-2018, 2018.

Liu, T., Liu, Q., Chen, Y., Wang, W., Zhang, H., Li, D., and Sheng, J.: Effect of aerosols on the macro-and micro-physical properties of warm clouds in the BeijingTianjin-Hebei region, Sci. Total Environ., 720, 137618, https://doi.org/10.1016/j.scitotenv.2020.137618, 2020.

Mamali, D., Marinou, E., Sciare, J., Pikridas, M., Kokkalis, P., Kottas, M., Binietoglou, I., Tsekeri, A., Keleshis, C., Engelmann, R., Baars, H., Ansmann, A., Amiridis, V., Russchenberg, H., and Biskos, G.: Vertical profiles of aerosol mass concentration de- rived by unmanned airborne in situ and remote sensing instruments during dust events, Atmos. Meas. Tech., 11, 2897-2910, https://doi.org/10.5194/amt-11-2897-2018, 2018.

Mamouri, R. E. and Ansmann, A.: Estimated desert-dust ice nuclei profiles from polarization lidar: methodology and case studies, Atmos. Chem. Phys., 15, 3463-3477, https://doi.org/10.5194/acp-15-3463-2015, 2015.

Mamouri, R.-E. and Ansmann, A.: Potential of polarization lidar to provide profiles of $\mathrm{CCN}-$ and INP-relevant aerosol parameters, Atmos. Chem. Phys., 16, 5905-5931, https://doi.org/10.5194/acp-16-5905-2016, 2016.

Marinou, E., Tesche, M., Nenes, A., Ansmann, A., Schrod, J., Mamali, D., Tsekeri, A., Pikridas, M., Baars, H., Engelmann, R., Voudouri, K.-A., Solomos, S., Sciare, J., Groß, S., Ewald, F., and Amiridis, V.: Retrieval of ice-nucleating particle concentrations from lidar observations and comparison with UAV in situ measurements, Atmos. Chem. Phys., 19, 11315-11342, https://doi.org/10.5194/acp-19-11315-2019, 2019.

Masonis, S. J., Anderson, T. L., Covert, D. S., Kapustin, V., Clarke, A. D., Howell, S., and Moore, K.: A study of the extinction-to-backscatter ratio of marine aerosol during the Shoreline Environment Aerosol Study, J. Atmos. Ocean. Tech., 20, 1388-1402, https://doi.org/10.1175/15200426(2003)020<1388:ASOTER>2.0.CO;2, 2003.

McCoy, D. T., Bender, F. M., Mohrmann, J. K. C., Hartmann, D. L., Wood, R., and Grosvenor, D. P.: The global aerosolcloud first indirect effect estimated using MODIS, MERRA, and AeroCom, J. Geophys. Res.-Atmos., 122, 1779-1796, https://doi.org/10.1002/2016JD026141, 2017.

Molod, A., Takacs, L., Suarez, M., and Bacmeister, J.: Development of the GEOS-5 atmospheric general circulation model: evolution from MERRA to MERRA2, Geosci. Model Dev., 8, 1339-1356, https://doi.org/10.5194/gmd-8-1339-2015, 2015.

Omar, A., Winker, D., Kittaka, C., Vaughan, M., Liu, Z., Hu, Y., Trepte, C., Rogers, R., Ferrare, R., Kuehn, R., and Hostetler, C.: The CALIPSO Automated Aerosol Classification and Lidar Ratio Selection Algorithm, J. Atmos. Ocean. Techn., 26, 1994 2014, https://doi.org/10.1175/2009JTECHA1231.1, 2009.

Omar, A. H., Won, J.-G., Winker, D. M., Yoon, S.-C., Dubovik, O., and McCormick, M. P.: Development of global aerosol models using cluster analysis of Aerosol Robotic Network (AERONET) measurements, J. Geophys. Res., 110, D10S14, https://doi.org/10.1029/2004JD004874, 2005.

Oreopoulos, L., Cho, N., and Lee, D.: Using MODIS cloud regimes to sort diagnostic signals of aerosol-cloud-precipitation interactions, J. Geophys. Res.-Atmos., 122, 5416-5440, https://doi.org/10.1002/2016JD026120, 2017.

Petters, M. D. and Kreidenweis, S. M.: A single parameter representation of hygroscopic growth and cloud condensation nucleus activity, Atmos. Chem. Phys., 7, 1961-1971, https://doi.org/10.5194/acp-7-1961-2007, 2007.

Quaas, J., Boucher, O., Bellouin, N., and Kinne, S.: Satellitebased estimate of the direct and indirect aerosol climate forcing, J. Geophys. Res.-Atmos., 113, D05204, https://doi.org/10.1029/2007JD008962, 2008.

Quaas, J., Arola, A., Cairns, B., Christensen, M., Deneke, H., Ekman, A. M. L., Feingold, G., Fridlind, A., Gryspeerdt, E., Hasekamp, O., Li, Z., Lipponen, A., Ma, P.-L., Mülmenstädt, J., Nenes, A., Penner, J. E., Rosenfeld, D., Schrödner, R., Sin- 
clair, K., Sourdeval, O., Stier, P., Tesche, M., van Diedenhoven, B., and Wendisch, M.: Constraining the Twomey effect from satellite observations: issues and perspectives, Atmos. Chem. Phys., 20, 15079-15099, https://doi.org/10.5194/acp-20-150792020, 2020.

Remer, L. A., Kaufman, Y. J., Tanré, D., Mattoo, S., Chu, D. A., Martins, J. V., Li, R. R., Ichoku, C., Levy, R. C., Kleidman, R. G., and Eck, T. F.: The MODIS aerosol algorithm, products, and validation, J. Atmos. Sci., 62, 947-973, https://doi.org/10.1175/JAS3385.1, 2005.

Rosenfeld, D., Andreae, M. O., Asmi, A., Chin, M., de Leeuw, G., Donovan, D. P., Kahn, R., Kinne, S., Kivekäs, N., Kulmala, M., and Lau, W.: Global observations of aerosol-cloudprecipitation-climate interactions, Rev. Geophys., 52, 750-808, https://doi.org/10.1002/2013RG000441, 2014.

Rosenfeld, D., Zheng, Y., Hashimshoni, E., Pöhlker, M. L., Jefferson, A., Pöhlker, C., Yu, X., Zhu, Y., Liu, G., Yue, Z., and Fischman, B.: Satellite retrieval of cloud condensation nuclei concentrations by using clouds as CCN chambers, P. Natl. Acad. Sci. USA, 113, 5828-5834, https://doi.org/10.1073/pnas.1514044113, 2016.

Schafer, J. S., Eck, T. F., Holben, B. N., Thornhill, K. L., Ziemba, L. D., Sawamura, P., Moore, R. H., Slutsker, I., Anderson, B. E., Sinyuk, A., Giles, D. M., Smirnov, A., Beyersdorf, A. J., and Winstead, E. L.: Intercomparison of aerosol volume size distributions derived from AERONET ground-based remote sensing and LARGE in situ aircraft profiles during the 2011-2014 DRAGON and DISCOVER-AQ experiments, Atmos. Meas. Tech., 12, 5289-5301, https://doi.org/10.5194/amt-12-5289-2019, 2019.

Schmale, J., Henning, S., Henzing, B., Keskinen, H., Sellegri, K., Ovadnevaite, J., Bougiatioti, A., Kalivitis, N., Stavroulas, I., Jefferson, A., and Park, M.: Collocated observations of cloud condensation nuclei, particle size distributions, and chemical composition, Scientific Data, 4, 1-27, https://doi.org/10.1038/sdata.2017.3, 2017.

Shinozuka, Y., Clarke, A. D., Nenes, A., Jefferson, A., Wood, R., McNaughton, C. S., Ström, J., Tunved, P., Redemann, J., Thornhill, K. L., Moore, R. H., Lathem, T. L., Lin, J. J., and Yoon, Y. J.: The relationship between cloud condensation nuclei (CCN) concentration and light extinction of dried particles: indications of underlying aerosol processes and implications for satellitebased CCN estimates, Atmos. Chem. Phys., 15, 7585-7604, https://doi.org/10.5194/acp-15-7585-2015, 2015.
Stier, P.: Limitations of passive remote sensing to constrain global cloud condensation nuclei, Atmos. Chem. Phys., 16, 6595-6607, https://doi.org/10.5194/acp-16-6595-2016, 2016.

Tackett, J. L., Winker, D. M., Getzewich, B. J., Vaughan, M. A., Young, S. A., and Kar, J.: CALIPSO lidar level 3 aerosol profile product: version 3 algorithm design, Atmos. Meas. Tech., 11, 4129-4152, https://doi.org/10.5194/amt-11-4129-2018, 2018.

Tesche, M., Ansmann, A., Müller, D., Althausen, D., Engelmann, R., Freudenthaler, V., and Groß, S.: Vertically resolved separation of dust and smoke over Cape Verde using multiwavelength Raman and polarization lidars during Saharan Mineral Dust Experiment 2008, J. Geophys. Res.-Atmos., 114, D13202, https://doi.org/10.1029/2009JD011862, 2009.

Tsekeri, A., Amiridis, V., Marenco, F., Nenes, A., Marinou, E., Solomos, S., Rosenberg, P., Trembath, J., Nott, G. J., Allan, J., Le Breton, M., Bacak, A., Coe, H., Percival, C., and Mihalopoulos, N.: Profiling aerosol optical, microphysical and hygroscopic properties in ambient conditions by combining in situ and remote sensing, Atmos. Meas. Tech., 10, 83-107, https://doi.org/10.5194/amt-10-83-2017, 2017.

Vaughan, M., Powell, K., Kuehn, R., Young, S., Winker, D., Hostetler, C., Hunt, W., Liu, Z., McGill, M., and Getzewich, B.: Fully Automated Detection of Cloud and Aerosol Layers in the CALIPSO Lidar Measurements, J. Atmos. Ocean. Tech., 26, 2034-2050, https://doi.org/10.1175/2009JTECHA1228.1, 2009.

Williamson, C. J., Kupc, A., Bilsback, K. R., Bui, T. P., Jost, P. C., Dollner, M., Froyd, K. D., Hodshire, A. L., Jimenez, J. L., Kodros, J. K., Luo, G., Murphy, D. M., Nault, B. A., Ray, E., Weinzierl, B., Yu, F., Yu, P., Pierce, J. R., and Brock, C. A.: ATom: In Situ Tropical Aerosol Properties and Comparable Global Model Outputs, ORNL DAAC, Oak Ridge, Tennessee, USA, https://doi.org/10.3334/ORNLDAAC/1684, 2019.

Winker, D. M., Vaughan, M. A., Omar, A., Hu, Y., Powell, K. A., Liu, Z., Hunt, W. H., and Young, S. A.: Overview of the CALIPSO mission and CALIOP data processing algorithms, J. Atmos. Ocean. Tech., 26, 2310-2323, https://doi.org/10.1175/2009JTECHA1281.1, 2009.

Zieger, P., Fierz-Schmidhauser, R., Weingartner, E., and Baltensperger, U.: Effects of relative humidity on aerosol light scattering: results from different European sites, Atmos. Chem. Phys., 13, 10609-10631, https://doi.org/10.5194/acp-13-106092013, 2013. 